\title{
Editorial: Cellulose dissolution and regeneration: systems and interactions
}

\author{
Björn LINDMAN, Bruno MEDRONHO and Hans THELIANDER
}

The interest in cellulose dissolution and regeneration is old but this topic has recently attracted strongly renewed attention. This is reflected in both applications- earlier and novel- and scientific controversies. This special issue attempts to connect a renewed fundamental understanding of molecular aspects with practical systems for dissolution and regeneration.

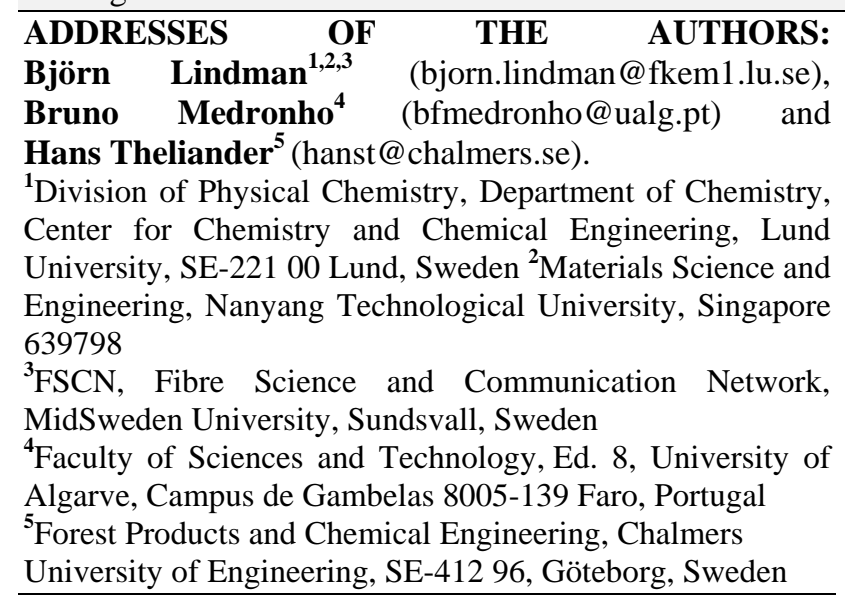

Cellulose is indeed a special material which offers a wide variety of applications hardly matched by any other natural or synthetic compound. A major concern in the field of cellulose is its limited solubility in water, which makes the processing rather challenging. Therefore, in recent years, cellulose dissolution and regeneration have become an increasingly active field of research. This is due both to the direct relevance for numerous production processes and applications and to more fundamental aspects. The problem of obtaining a picture of molecular processes is not trivial since cellulose solvents are of remarkably different nature and thus the understanding of the delicate balance between the different interactions involved becomes non-trivial. There is a current discussion in literature on the balance between hydrogen bonding and hydrophobic interactions in controlling the solution behavior of cellulose (Medronho et al. 2012; Glasser et al. 2012).

\section{Dissolution and regeneration involve breaking of hydrogen bonds}

A typical statement in literature of the last decade that deals with cellulose dissolution and regeneration is: "cellulose itself is insoluble in water due to the many and strong hydrogen bonds". Consequently: "the key to the solution of this problem of cellulose solubility is to search for a solvent that can destroy effectively the interchain hydrogen bonding in cellulose”.

If it is true that there are in solid cellulose strong hydrogen bonds between cellulose molecules and that these need to be broken to achieve dissolution, it is certainly not less true that cellulose molecules are not transferred from the solid state into a situation where there are no intermolecular interactions (vacuum). Instead they are transferred into a medium where cellulose molecules experience other intermolecular interactions of considerable strength. For cellulose molecules in water there are strong water-cellulose hydrogen bonds, in fact of the same strength as cellulose-cellulose hydrogen bonds itself. In other solvents, the cellulose-solvent interactions may be of similar strength or slightly weaker. The conclusion seems clear: other interactions than hydrogen bonding alone must explain the insolubility of cellulose in water and in other solvents (Lindman et al. 2010).

In fact, regeneration of cellulose from a solvent would face the same problem of breaking hydrogen bonds as on dissolution. Of course, no such observations have been made. In reality, there is a fast phase separation process going on as soon as the solvency conditions are worsened.

\section{Amphiphilic solvents for amphiphilic cellulose}

Recently, the "hydrogen bond mechanism" has been intensively discussed in literature and has been challenged by general arguments regarding interactions, as well as by simulations and experimental studies. Not least have computer simulations provided a deepened understanding.

Cellulose has both hydrophobic and hydrophilic segments, and thus should have significant amphiphilic properties; the $\mathrm{C}-\mathrm{H}$ and $\mathrm{C}-\mathrm{O}$ bonds are distinctly segregated in space. These special structural features, although known for several years, not always deserve the right relevance in discussions (Yamane et al. 2006; Biermann et al. 2001). The same is valid for the role of cellulose charges and the concomitant ion entropy effects in dissolution or how important the kinetic aspects in a certain dissolution process are.

The role of amphiphilic solvents or additives in cellulose dissolution is now becoming clearer with support coming from both theoretical and non theoretical perspectives (Bergenstråhle et al. 2008; Bergenstråhle et al. 2010; Yan, Gao 2008; Cai, Zhang 2005). The amphiphilic character of successful solvents such as $\mathrm{N}$ methylmorpholine-N-oxide (cf. Lyocell process) or ionic liquids is also striking (Medronho, Lindman 2014). However, in several other solvent systems the mechanisms are more obscure and there are still important needs for further research that establishes the crucial roles of different interactions.

\section{What can be found in this special issue?}

Key aspects such as those described above are currently employed in developing solvents and regeneration systems for cellulose and this issue covers most of them. We may divide this issue in five main themes intimately interconnected:

1)Characterization of pulps, cellulose solvents and cellulose dopes;

2)Dissolution mechanisms; 
3)Theoretical work on cellulose dissolution;

4)Regeneration mechanisms;

5)New solvents and regenerated materials;

Regarding the first sub-topic, Budtova et al. (Budtova, Navard 2015) discuss the determination of activation energies and concomitant solvent characterization via shear viscosity measurements. On the other hand, Meister and Kosan (2015) describe a vast number of analytical methods for chemical and physical characterization of pulps, dopes and regenerated materials.

When it comes to the dissolution mechanisms, a general overview on the evidences of the role of hydrophobic interactions in cellulose dissolution is given (Medronho et al. 2015). Due to its remarkable potential in substitution some of the hazardous routes available today, the mechanism of cellulose dissolution in strong alkali is highlighted both using native cellulose nanofibers (Yamane et al. 2015) and a modified cellulose derivative (Wang et al. 2015). Ionic liquids (ILs) are also a very promising class of solvents and their mixtures with dipolar aprotic solvents and how these affect the interactions between cellulose and the solvent mixtures are discussed (Bioni et al. 2015).

The third topic focuses on theoretical work. The watercellulose interaction receives special attention; the effect of electronic polarization on cellulose-water interactions is studied by all-atom computer simulations (Stenqvist et al. 2015), and also the solubility of model cellulose fragments in water under supercritical conditions is investigated (Wohlert et al. 2015). Furthermore, the use of molecular dynamics to study the dissolution of cellobiose under strongly alkaline conditions is treated (Miyamoto et al. 2015).

The last part of this issue highlights the regeneration of cellulose. A general review is provided (Yamane 2015) as well as a treatise with focus on the role of co-solvents in the coagulation of cellulose in ILs (Hedlund et al. 2015). Finally, new solvents and regenerated materials (fibers and films) are discussed and characterized (Sixta et al. 2015; Kargl et al. 2015).

\section{Acknowledgements}

Support from the Portuguese Foundation for Science and Technology (FCT project PTDC/AGR-TEC/4049/2012 and post-doc grant: $\mathrm{SFRH/BPD/74540/2010)}$ is acknowledged. Financial support was also received from Södra Skogsägarnas Stiftelse, and Stiftelsen Nils och Dorthi Troëdssons forskningsfond.

\section{Literature}

Bergenstråhle, M., Mazeau, K. and Berglund, L. A. (2008): Molecular modeling of interfaces between cellulose crystals and surrounding molecules: Effects of caprolactone surface grafting, Eur Polym J 44(11), 3662-3669.

Bergenstråhle, M., Wohlert, J., Himmel, M. E. and Brady, J. W. (2010): Simulation studies of the insolubility of cellulose, Carbohyd Res 345(14), 2060-2066.

Biermann, O., Hadicke, E., Koltzenburg, S. and Muller-Plathe, F. (2001): Hydrophilicity and lipophilicity of cellulose crystal surfaces, Angew Chem Int Edit 40(20), 3822-3825.

Bioni, T. A., Arêas, E. P. G., Couto, L. G., Favarin, G. and El Seoud, O. A. (2015): Dissolution of cellulose in mixtures of ionic liquid and molecular solvents: Relevance of solvent-solvent and cellulose-solvent interactions, Nordic Pulp and Paper Research Journal 30(1), 105-111.
Budtova, T. and Navard, P. (2015): Viscosity-temperature dependence and activation energy of cellulose solutions, Nordic Pulp and Paper Research Journal 30(1), 99-104.

Cai, J. and Zhang, L. (2005): Rapid dissolution of cellulose in $\mathrm{LiOH} / \mathrm{Urea}$ and $\mathrm{NaOH} /$ Urea aqueous solutions, Macromol Biosci 5(6), 539-548.

Glasser, W. G., Atalla, R. H., Blackwell, J., Brown, R. M., Burchard, W., French, A. D., Klemm, D. O., Navaed, P. and Nishiyama, Y. (2012): About the structure of cellulose: debating the Lindman hypothesis, Cellulose 19(3), 589-598.

Hedlund, H., Köhnke, T. and Theliander, H. (2015): Coagulation of EmimAc-cellulose solutions: dissolution-precipitation disparity and effects of non-solvents and cosolvent, Nordic Pulp and Paper Research Journal 30(1), 32-42.

Kargl, R., Mohan, T., Ribitsch, V., Saake, B., Puls, J. and Kleinschek, K. S. (2015): Cellulose thin films from ionic liquid solutions, Nordic Pulp and Paper Research Journal 30(1), 6-13.

Lindman, B., Karlström, G. and Stigsson, L. (2010): On the mechanism of dissolution of cellulose, J Mol Liq 156(1), 76-81.

Medronho, B., Duarte, H., Alves, L., Antunes, F. E., Romano, A. and Lindman, B. (2015): Probing Cellulose Amphiphilicity, Nordic Pulp and Paper Research Journal 30(1), 58-56.

Medronho, B. and Lindman, B. (2014): Competing forces during cellulose dissolution: From solvents to mechanisms, Curr. Opin. Colloid Interface Sci. 19, 32-40.

Medronho, B., Romano, A., Miguel, M. G., Stigsson, L. and Lindman, B. (2012): Rationalizing cellulose (in)solubility: reviewing basic physicochemical aspects and role of hydrophobic interactions, Cellulose 19(3), 581-587.

Meister, F. and Kosan, B. (2015): A tool box for characterization of pulps and cellulose dopes in Lyocell technology, Nordic Pulp and Paper Research Journal 30(1), 112-120.

Miyamoto, H., Schnupf, U., Ueda, K. and Yamane, C. (2015): Dissolution mechanism of cellulose in a solution of aqueous sodium hydroxide revealed by molecular dynamics simulations, Nordic Pulp and Paper Research Journal 30(1), 67-77.

Sixta, H., Michud, A., Hauru, L., Asaadi, S., Ma, Y., King, A. W. T., Kilpeläinen, I. and Hummel, M. (2015): Ioncell-F: A Highstrength regenerated cellulose fibre, Nordic Pulp and Paper Research Journal 30(1), 43-57.

Stenqvist, B., Wernersson, E. and Lund, M. (2015): CelluloseWater Interactions: Effect of electronic polarizability, Nordic Pulp and Paper Research Journal 30(1), 26-31.

Wang, W., Li, F., Yu, J., Budtova, T. and Navard, P. (2015): A thermal behavior of low-substituted hydroxyethyl cellulose and cellulose solutions in $\mathrm{NaOH}$-water, Nordic Pulp and Paper Research Journal 30(1), 20-25.

Wohlert, J., Tolonen, L. K. and Bergenstråhle-Wohlert, M. (2015): A simple model for cellulose solubility in supercritical water, Nordic Pulp and Paper Research Journal 30(1), 14-19.

Yamane, C. (2015): Structure formation of regenerated cellulose from its solution and resultant features of high wettability: A review, Nordic Pulp and Paper Research Journal 30(1), 78-91.

Yamane, C., Abe, K., Satho, M. and Miyamoto, H. (2015): Dissolution of cellulose nanofibers in aqueous sodium hy-droxide solution, Nordic Pulp and Paper Research Journal 30(1), 92-98.

Yamane, C., Aoyagi, T., Ago, M., Sato, K., Okajima, K. and Takahashi, T. (2006): Two different surface properties of regenerated cellulose due to structural anisotropy, Polym J 38(8), 819-826.

Yan, L. F. and Gao, Z. J. (2008): Dissolving of cellulose in $\mathrm{PEG} / \mathrm{NaOH}$ aqueous solution, Cellulose 15(6), 789-796. 